\title{
Analysing limitations of the FlowCyl as a one-point viscometer test for cement paste
}

Cepuritis, Rolands; Skare, Elisabeth L.; Ramenskiy, Evgeny; Mørtsell, Ernst; Smeplass, Sverre; Li, Shizhao; Jacobsen, Stefan; Spangenberg, Jon

Published in:

Construction and Building Materials

Link to article, DOI:

10.1016/j.conbuildmat.2019.05.127

Publication date:

2019

Document Version

Peer reviewed version

Link back to DTU Orbit

Citation $(A P A)$ :

Cepuritis, R., Skare, E. L., Ramenskiy, E., Mørtsell, E., Smeplass, S., Li, S., Jacobsen, S., \& Spangenberg, J. (2019). Analysing limitations of the FlowCyl as a one-point viscometer test for cement paste. Construction and Building Materials, 218, 333-340. https://doi.org/10.1016/j.conbuildmat.2019.05.127

\section{General rights}

Copyright and moral rights for the publications made accessible in the public portal are retained by the authors and/or other copyright owners and it is a condition of accessing publications that users recognise and abide by the legal requirements associated with these rights.

- Users may download and print one copy of any publication from the public portal for the purpose of private study or research.

- You may not further distribute the material or use it for any profit-making activity or commercial gain

- You may freely distribute the URL identifying the publication in the public portal 
2 Analysing limitations of the FlowCyl as a one-point viscometer test for cement paste

3

4 Rolands $\underline{\text { Cepuritis }}^{1,2}$, Elisabeth L. $\underline{\text { Skare }}^{1,3}$, Evgeny $\underline{\text { Ramenskiy }}^{1,3}$, Ernst $\underline{\text { Mørtsell }}^{1,5}$,

5 Sverre $\underline{\text { Smeplass }}^{1,4}$, Shizhao $\underline{\mathrm{Li}}^{3}$, Stefan $\underline{\text { Jacobsen }}^{1}$, Jon $\underline{\text { Spangenberg }}{ }^{3}$

6

71 Department of Structural Engineering, Norwegian University of Science and

8 Technology, NO-7491 Trondheim, Norway

$9{ }^{2}$ Norcem AS (HeidelbergCementGroup), R\&D Department, Setreveien 2, Postboks 38, 10 NO-3950 Brevik, Norway

$11{ }^{3}$ Department of Mechanical Engineering, Technical University of Denmark, 2800

12 Lyngby, Denmark

$13{ }^{4}$ Skanska Norge AS, Drammensveien 60, PO Box 1175, NO-0107 Oslo, Norway
${ }^{5}$ NorBetong AS (HeidelbergCementGroup), Heggstadmyra 6, NO-7080 Heimdal, Norway
Abstract: The FlowCyl is a simple flow viscometer - a modification of the Marsh Cone test apparatus - developed to quantify the flow behaviour of cement pastes. The FlowCyl gives a one-parameter characterisation of rheology called the flow resistance ratio or $\lambda_{Q}$, which is defined as the average ratio between the flow loss of a measured fluid and theoretical flow of an ideal fluid. This paper reports a study on the limitations of the FlowCyl and appurtenant flow resistance ratio. The investigation includes rheological measurements of cement pastes incorporating crushed aggregate fines with a diameter below $125 \mu \mathrm{m}$ and development of a numerical model in order to analyse the flow condition inside the FlowCyl. The numerical simulations are carried out both with the Bingham- and Herschel-Bulkley material model of the rheometer data. A comparison with the experimental $\lambda_{\mathrm{Q}}$ results illustrates that only a minor error is introduced when describing the flow of cement paste in the FlowCyl with a twoparameter model (Bingham material model) as compared to a three-parameter model (HershelBulkley model). The results also show that the one-parameter characterisation (i.e. $\lambda_{\mathrm{Q}}$ ) mainly correlates to the plastic viscosity in the Bingham material model, while the yield stress only correlates if the dosage of superplasticizer per mass of cement is kept constant. The numerical simulations show that high shear rates at the outlet of the FlowCyl are responsible for the difference in the correlations. 
Keywords: Rheology, cement paste, FlowCyl, yield stress, plastic viscosity

\section{INTRODUCTION}

As pointed out by Ferraris et. al [1], determining rheology properties by testing concrete is not always practical, easy, and economical, because execution of numerous concrete tests requires a large amount of material and manpower. Therefore, there is a need for simpler and easier laboratory approaches. It has been demonstrated that rheological measurements of cement paste can be used as a reasonable indicator of concrete rheology [1], [2], [3].

Fresh cement paste is a fluid that, just like concrete, exhibits a yield stress, requiring a minimum stress to initiate flow. Below the yield stress, cement paste behaves like a solid, which typically is a result of a three-dimensional microstructure at low stresses [4]. Above the yield stress, cement paste on the contrary deforms as a fluid according to a viscosity function that is shear rate dependent. The rheological behaviour of cement paste can be quantified by the usage of a rheometer, for example, with a parallel plate, cone and plate, coaxial cylinder, or Couette geometry [5]. The shear stress (or viscosity) as a function of shear rate and a best-fit match to the data determines the appropriate constitute law, e.g. the Bingham- or Herschel-Bulkley (HB) material model [5].

As pointed out by Shaughnessy and Clark [6], measuring the rheological properties of cement paste is not a straightforward task, and substantial care must be taken prior, during and after the measurements. The most common measurement techniques, procedures and challenges were recently thoroughly reviewed by some of the authors of this paper. The review can be found in the following reference [7]. Although highly accurate rheometers are available, simple empirical test methods for rheological examination of cement paste are also quite popular, for both research and industrial purposes. This is due to relatively complex procedures of performing measurements with the rheometers, but even more importantly due to their cost. One of the most popular of the applied empirical methods include a range of mini slump-cone geometries that mainly provide the single empirical parameter, slump flow (spread diameter of the mixture), which relates to the yield stress of the cement paste [1], [8]. Another set of tests are the orifice viscometers, where the fresh cement paste flows out of different funnel-shaped 
containers through a narrow orifice. The mass flux or flow time is registered as the test result. Some of the most popular orifice viscometers are the Marsh cone [9], [10], mini V-funnel [1], and FlowCyl [2], [3], [11].

The FlowCyl test characterizes the rheological behaviour of cement pastes via one parameter, the flow resistance ratio (denoted $\lambda_{\mathrm{Q}}$ ), which is described in more detail later in the paper. This test method has been successfully used to predict the workability of conventional (vibrated) normal-weight concrete mixes with consistencies of up to about $240 \mathrm{~mm}$ of slump, which was based on natural sand and cement paste with relatively low fines content [2]. Later, the same was shown to be possible for lightweight aggregate concrete that was based on natural sand and coarse lightweight aggregates [3]. However, in a series of further studies [11], [12], [13] it was demonstrated that the FlowCyl test result has limitations when applied to self-compacting concrete (SCC) mixes and mixes incorporating high amounts of crushed sand fines when the amount of superplasticiser was below the assumed saturation level. In the study, by Mørtsell and Smeplass [11] the hypothesis was that the proportioning model where the FlowCyl is used to characterise the viscous phase of the concrete (filler modified cement paste = matrix) would work even better with the matrix-dominated SCC mixes. Then the workability of the SCC mixes tested would be a unique function of the flow resistance ratio of the matrix determined with the FlowCyl and the volume of the matrix according to the Particle-Matrix concrete proportioning model [2]. However, the results revealed that to achieve a slump-flow measurement of approx. $650 \mathrm{~mm}$, the necessary matrix volume was $40-80 \mathrm{l} / \mathrm{m}^{3}$ lower for the mixes based on the highstrength ordinary Portland cement (OPC) than for the regular OPC mixes, when all other parameters (including $\lambda_{\mathrm{Q}}$ values) were comparable. In other words, the researchers did not find a simple correlation between the flow resistance ratio of the matrix and the workability of the SCC. Smeplass and Mørtsell [11] suggested that the problem potentially was in the measuring device used for the characterisation of the matrix, i.e. the FlowCyl. They theorized that the problem with the FlowCyl was that it gives only a single value, whereas the matrix is at least a two-parameter fluid and thus there is a need to get a more fundamental understanding of the limitations of this equipment.

In this paper, the objective is for the first time to analyse the limitations of the flow resistance ratio when used as a one-point parameter to describe the flow behaviour of fresh filler modified cement paste. Hereto, FlowCyl and rheometer measurements of filler modified cement pastes 
100 that cover a broad interval of flowabilities are performed and correlated. In addition, a 101 numerical model is employed to simulate the FlowCyl tests and thereby assist in 102 understanding/estimating the error that is introduces by going from a three-parameter $(\mathrm{H}-\mathrm{B}$ 103 material model: $\tau=\tau_{0}+K \dot{\gamma}^{n}$, where $\tau_{0}$ is H-B yield stress [Pa], $\mathrm{K}$ is consistency factor [Pa $\mathrm{s}^{\mathrm{n}}$ ] 104 and $\mathrm{n}$ is flow index [-]) to a two-parameter (Bingham material model: $\tau=\tau_{0}+\mu \dot{\gamma}$, where $\tau_{0}$ is 105 Bingham's yield stress [Pa], $\mu$ is Bingham's plastic viscosity [Pa s], while $\tau$ and $\dot{\gamma}$ are the 106 corresponding yield stress $[\mathrm{Pa}]$ and shear rate $[1 / \mathrm{s}]$ ) to a one-parameter (flow resistance ratio)

107 flow characterization of cement pastes.

108

\section{EXPERIMENTS}

\section{2.1. Materials}

111 Three different types of crushed aggregate fines were included in the cement pastes in order to

112 obtain cement pastes with different rheological behaviour. All of the crushed fines originated 113 from the same granitic rock type (typical mineralogical composition of the parent rock: feldspar $11448 \%$, quartz $48 \%$, amphibolite $2 \%$, mica $1 \%$, chlorite $1 \%$ ) and were produced in the same 115 way. The production process included four steps of rock crushing followed by a system of air116 classification that was utilised to extract the generated fines from the crushed aggregates. The 117 three types of crushed fines were extracted at different steps in the air-classification process and 118 thus the main difference between them was their PSD. The different types of fines were denoted 119 as (F)-PSD, (C)-PSD and (I)-PSD. The maximum particle size for all three types of fines was 120 adjusted to be the same by mechanical sieving via a sieve with square opening of $125 \mu \mathrm{m}$ edge 121 length. The PSD of the fines, see Figure 1, was determined by a SediGraph, which is a PSD 122 measurement tool that measures the particle sedimentation speed through x-ray absorption and 123 calculates the equivalent particle diameter based on Stoke's law [14]. The oven-dry particle

124 density for all of the crushed fines was determined with a helium pycnometer to be the same, 125 i.e. $2.65 \mathrm{~g} / \mathrm{cm}^{3}$. 


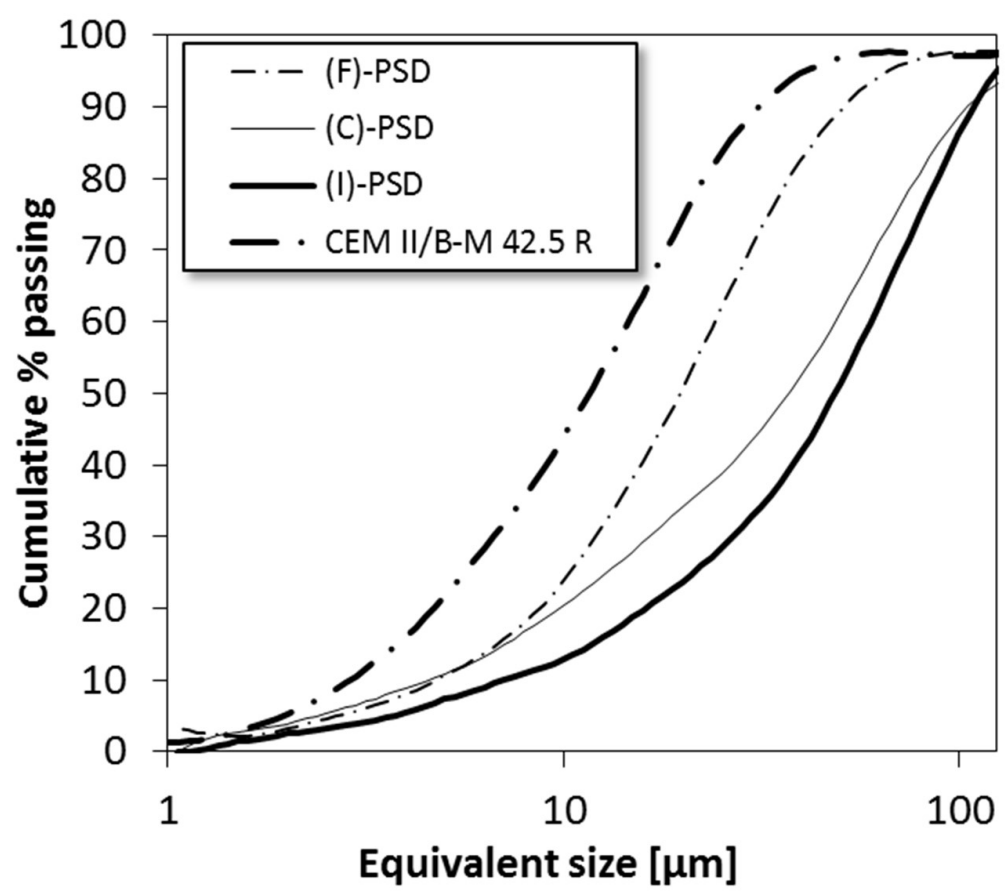

127

128

129

130 Blended cement with a particle density of $3.0 \mathrm{~g} / \mathrm{cm}^{3}$ incorporating $18.1 \%$ of fly-ash and $5 \%$

Figure 1: PSDs of the crushed aggregate fines and cement used for the experiments.

of gypsum (CEM II/B-M 42.5 R) from Norcem AS was used in all the cementitious mixes. The mineralogical composition of the clinker of the cement was $\mathrm{C}_{3} \mathrm{~S}: 61.0 \% ; \mathrm{C}_{2} \mathrm{~S}: 14.2 \% ; \mathrm{C}_{3} \mathrm{~A}$ : $8.8 \%$; $\mathrm{C}_{4} \mathrm{AF}: 9.3 \%$; free $\mathrm{CaO}: 1.7 \%$; other minerals: $5.0 \%$. The $\mathrm{Na}_{2} \mathrm{O}$-eq. content of the cement was $1.3 \%$. The Blaine value was determined to be $422 \mathrm{~m}^{2} / \mathrm{kg}$ and the PSD of the cement determined with the SediGraph is shown in Figure 1. Polycarboxylate ether (PCE) based superplasticiser (SP) Dynamon SR-N (solids content of $19.5 \%$; liquid density of $1.05 \mathrm{~g} / \mathrm{cm}^{3}$ ) from Mapei was used.

\subsection{Cement paste compositions}

An overview of the studied filler modified cement paste compositions is given in Table 1. The mixes were divided into " $A$ "-series and "B-series. The "A"-series represents mixes where three different $w / c$ ratios $(0.4,0.55$ and 0.70$)$ were combined with the three different types of crushed fines. In addition, for every w/c ratio, three different fi/c ratios were employed. The w/c and fi/c ratios were chosen with the goal of covering the range that is practically used in ready-mix concrete production with crushed sand in Norway. For the "A"-series mixes the dosage of SP was fixed at $0.75 \%$ of the total cement mass. In the "B"-series, the SP dosage was varied for 
147 the mixes with (I)-PSD fines and w/c ratio 0.4 and 0.55 from the "A"-series, i.e. A10-A15. The

148 SP dosage was increased to $1.0 \%, 1.25 \%, 1.5 \%$ and $1.75 \%$ of the total cement mass.

149

150 Table 1: Overview of the studied filled modified cement paste compositions.

\begin{tabular}{|c|c|c|c|c|c|c|c|c|c|c|c|}
\hline $\begin{array}{l}\text { Mix } \\
\text { No. }\end{array}$ & $\mathbf{w} / \mathbf{c}$ & $\begin{array}{c}\text { SP } \\
{[\%]}\end{array}$ & fi/c & PSD & $\begin{array}{c}\text { Solid } \\
\text { volume } \\
\text { fraction } \\
\Phi_{s}\end{array}$ & $\begin{array}{l}\text { Mix } \\
\text { No. }\end{array}$ & $\mathbf{w} / \mathbf{c}$ & $\begin{array}{c}\text { SP } \\
{[\%]}\end{array}$ & fi/c & PSD & $\begin{array}{c}\text { Solid } \\
\text { volume } \\
\text { fraction } \\
\Phi_{s}\end{array}$ \\
\hline A-1 & 0.4 & 0.75 & 0.28 & (C) & 0.516 & B-1 & 0.40 & 1.00 & 0.28 & (I) & 0.516 \\
\hline A-2 & 0.4 & 0.75 & 0.36 & (C) & 0.531 & B-2 & 0.40 & 1.00 & 0.36 & (I) & 0.531 \\
\hline A-3 & 0.4 & 0.75 & 0.44 & (C) & 0.545 & B-3 & 0.40 & 1.00 & 0.44 & (I) & 0.545 \\
\hline A-4 & 0.55 & 0.75 & 0.51 & (C) & 0.477 & B-4 & 0.40 & 1.25 & 0.28 & (I) & 0.515 \\
\hline A-5 & 0.55 & 0.75 & 0.59 & (C) & 0.490 & B-5 & 0.40 & 1.25 & 0.36 & (I) & 0.530 \\
\hline A-6 & 0.55 & 0.75 & 0.67 & (C) & 0.502 & B-6 & 0.40 & 1.25 & 0.44 & (I) & 0.545 \\
\hline A-7 & 0.7 & 0.75 & 0.68 & (C) & 0.444 & B-7 & 0.40 & 1.50 & 0.28 & (I) & 0.515 \\
\hline A-8 & 0.7 & 0.75 & 0.76 & (C) & 0.456 & B-8 & 0.40 & 1.50 & 0.36 & (I) & 0.530 \\
\hline A-9 & 0.7 & 0.75 & 0.82 & (C) & 0.464 & B-9 & 0.40 & 1.50 & 0.44 & (I) & 0.544 \\
\hline A-10 & 0.4 & 0.75 & 0.28 & (I) & 0.516 & B-10 & 0.40 & 1.75 & 0.28 & (I) & 0.515 \\
\hline A-11 & 0.4 & 0.75 & 0.36 & (I) & 0.531 & B-11 & 0.40 & 1.75 & 0.36 & (I) & 0.530 \\
\hline A-12 & 0.4 & 0.75 & 0.44 & (I) & 0.545 & \begin{tabular}{|l|} 
B-12 \\
\end{tabular} & 0.40 & 1.75 & 0.44 & (I) & 0.544 \\
\hline A-13 & 0.55 & 0.75 & 0.51 & (I) & 0.477 & B-13 & 0.55 & 1.00 & 0.51 & (I) & 0.477 \\
\hline A-14 & 0.55 & 0.75 & 0.59 & (I) & 0.490 & B-14 & 0.55 & 1.00 & 0.59 & (I) & 0.490 \\
\hline A-15 & 0.55 & 0.75 & 0.67 & (I) & 0.502 & B-15 & 0.55 & 1.00 & 0.67 & (I) & 0.502 \\
\hline A-16 & 0.7 & 0.75 & 0.68 & (I) & 0.444 & B-16 & 0.55 & 1.25 & 0.51 & (I) & 0.477 \\
\hline A-17 & 0.7 & 0.75 & 0.76 & (I) & 0.456 & \begin{tabular}{|l|} 
B-17 \\
\end{tabular} & 0.55 & 1.25 & 0.59 & (I) & 0.490 \\
\hline A-18 & 0.7 & 0.75 & 0.82 & (I) & 0.464 & B-18 & 0.55 & 1.25 & 0.67 & (I) & 0.502 \\
\hline A-19 & 0.4 & 0.75 & 0.28 & (F) & 0.516 & B-19 & 0.55 & 1.50 & 0.51 & (I) & 0.477 \\
\hline A-20 & 0.4 & 0.75 & 0.36 & (F) & 0.531 & \begin{tabular}{|l|} 
B-20 \\
\end{tabular} & 0.55 & 1.50 & 0.59 & (I) & 0.490 \\
\hline A-21 & 0.4 & 0.75 & 0.44 & (F) & 0.545 & B-21 & 0.55 & 1.50 & 0.67 & (I) & 0.502 \\
\hline A-22 & 0.55 & 0.75 & 0.51 & (F) & 0.477 & B-22 & 0.55 & 1.75 & 0.51 & (I) & 0.477 \\
\hline A-23 & 0.55 & 0.75 & 0.59 & $(\mathrm{~F})$ & 0.490 & B-23 & 0.55 & 1.75 & 0.59 & (I) & 0.489 \\
\hline A-24 & 0.55 & 0.75 & 0.67 & $(\mathrm{~F})$ & 0.502 & B-24 & 0.55 & 1.75 & 0.67 & (I) & 0.502 \\
\hline A-25 & 0.7 & 0.75 & 0.68 & $(\mathrm{~F})$ & 0.444 & & & & & & \\
\hline A-26 & 0.7 & 0.75 & 0.76 & (F) & 0.456 & & & & & & \\
\hline A-27 & 0.7 & 0.75 & 0.82 & (F) & 0.464 & & & & & & \\
\hline
\end{tabular}

Abbreviations used in the table:

$\mathbf{w} / \mathbf{c}=$ water-to-cement ratio by mass.

$\mathbf{S P}=$ superplasticiser dosage by mass of cement.

$\mathbf{f i} / \mathbf{c}=$ crushed fines-to-cement ratio by volume.

PSD $=$ particle size distribution of the crushed fines.

151

152

2.3. Methods

153 Mixing of the filler modified cement pastes was carried out following a routine investigated

154 and described by $\mathrm{Ng}$. et. al. [15]. This routine was chosen because, as reported by Ng. et. al.

155 [15], it provides a level of shear rates in the fresh mix that remedy too excessive temperature 
156 rise and/ or air entrainment during the material preparation. The FlowCyl and rheometer

157 measurements were started exactly 10 minutes after beginning the mixing procedure.

158

159 The test setup for the FlowCyl and its geometry is presented in Figure 2. The FlowCyl 160 measurements followed the same routine as reported in [16]. During a measurement, the 161 FlowCyl is filled with cement paste up to the level of $15 \mathrm{~mm}$ below the top edge, while the 162 outlet is blocked. Then the outlet is opened and the mass of the cement paste in the bowl under 163 the FlowCyl is registered with a sampling rate of $2 \mathrm{sec}$. Subsequently, the volumetric flow is 164 analysed from the cement paste has a height of $35 \mathrm{~cm}$ in the FlowCyl until it reaches $15 \mathrm{~cm}$ in 165 order to extract the flow resistance ratio (i.e. $\lambda_{\mathrm{Q}}$ ), which is a dimensionless single parameter 166 proposed by Mørtsell [2] that characterise the flowability of the cement paste. The flow 167 resistance ratio is defined as the difference in volumetric flow rate between the tested material 168 (fresh cement paste) and an "ideal" fluid [2] with no internal flow resistance and no external 169 cohesion or friction, i.e. the flow rate for an ideal fluid is only affected by gravity (the actual 170 expected volumetric flow rate, as function of the fluid height in the FlowCyl is provided in the 171 references [2] and [3]). It is given by the expression:

$$
\lambda_{Q}=F_{t} / F_{i},
$$

173 where $F_{t}$ is the average difference between the theoretical flow rate of an "ideal" fluid and the 174 measured flow rate of the tested cement paste; and $F_{i}$ is the average flow rate of the "ideal" 175 fluid. By definition, the "ideal" fluid has a $\lambda_{Q}$ value of 0.0 , while the theoretical upper limit of 176 the $\lambda_{\mathrm{Q}}$ value for a viscous fluid is 1.0 [2] [2], [3]. More details on the FlowCyl and the 177 mathematical derivation of $\lambda_{\mathrm{Q}}$ can be found in [2], [3], [11]. 


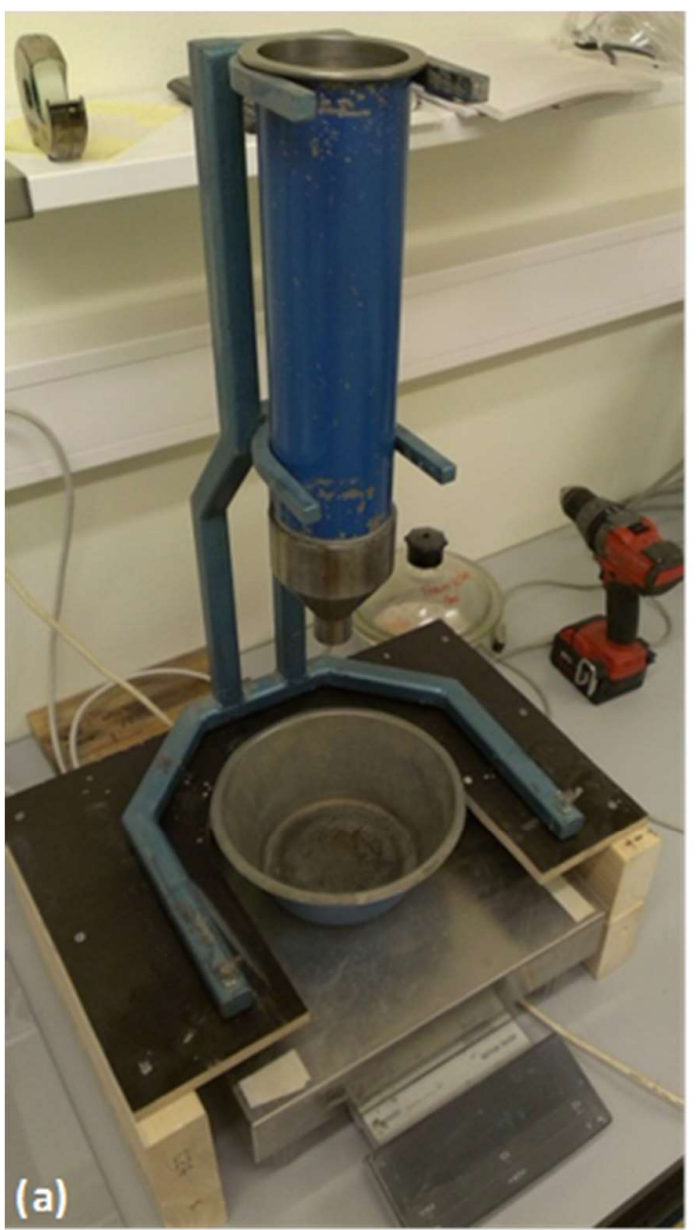

179

180

181

182

183

184

185

186

187

188

189

190

191

192 parameters and 0.01 units for the flow resistance ratio.

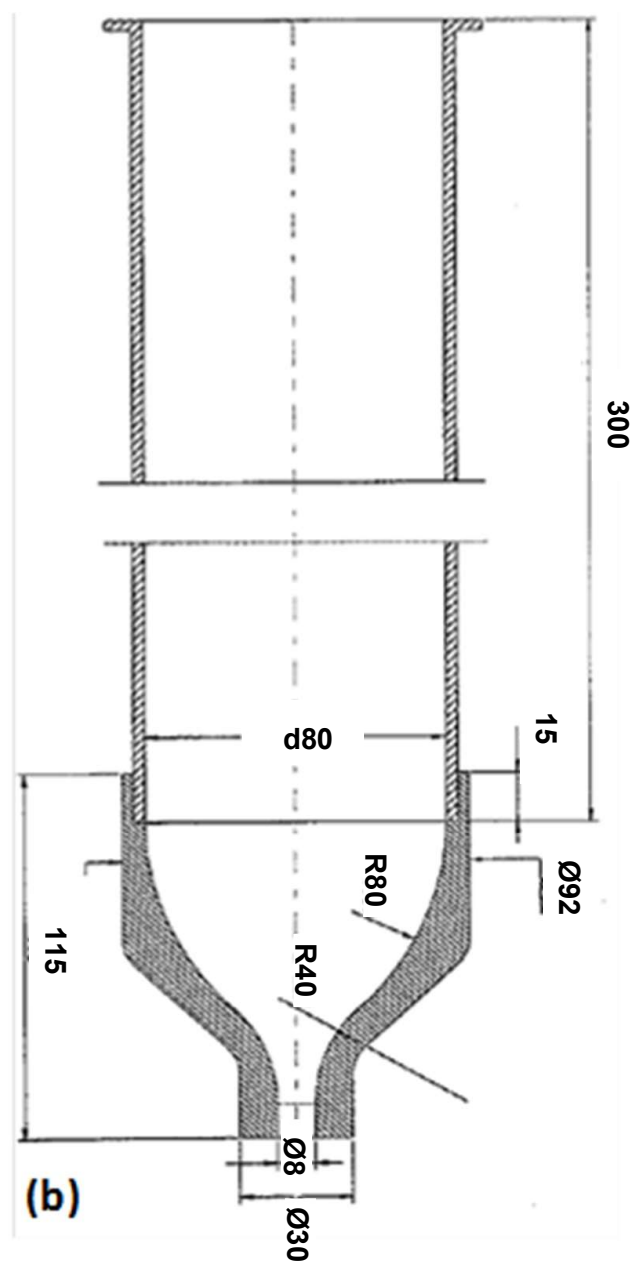

$\stackrel{\omega}{\circ}$

Figure 2: (a) the FlowCyl test apparatus; (b) the exact geometry of the FlowCyl test apparatus. Note that the lengths and radii are given in $\mathrm{mm}$.

The rheometer measurements were done on a Physica MCR 300 rheometer (Anton Paar) with a bob-in-a-cup geometry, see Figure 3. The geometry and the used measurement routine were the same, as reported in [17]. Mathematical regression was applied on the measured down (decreasing shear rate) flow-curve data in order to obtain the Bingham and H-B material model parameters [5]. In [17], also details about the uncertainty for both the Physical MCR 300 rheometer and FlowCyl measurements can be found. It was shown in [17] that for very similar cement pastes as studied in this paper, the standard deviation for 5 repeated measurements on the same mix composition, was approximately $0.9 \mathrm{MPa}$ and $0.01 \mathrm{~Pa} \cdot \mathrm{s}$ for the Bingham 


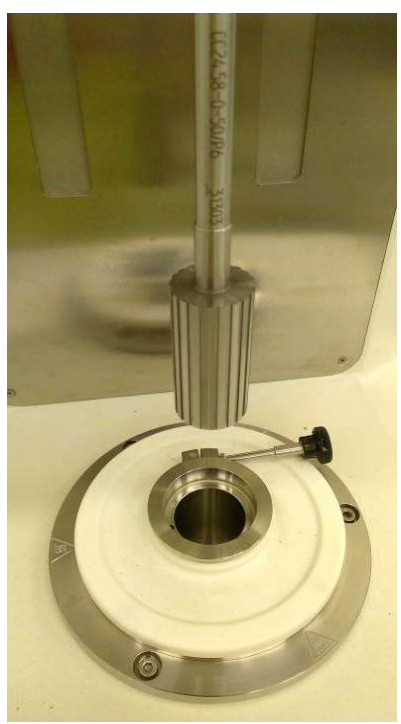

Figure 3: The bob-in-a-cup geometry used for the experiments. The surfaces of the bob have been roughened to prevent slip.

\section{NUMERICAL MODEL}

In the literature, numerical models have successfully been utilized to analyse different topics related to fresh cementitious materials, e.g. flow in reinforced formwork [18], [19], [20], gravity induced aggregate migration [21], [22], [23], [24], flow of fibers [25], [26], pumping [27], and flow conditions in rheological characterization tools [28], [29]. As mentioned in the introduction, in this study a computational fluid dynamics (CFD) model was used to analyse the flow behaviour in the FlowCyl. The CFD model was developed in the commercial software Flow3D that has been found to be very applicable for simulations of fresh cementitious materials [30]. Flow3D utilizes the finite volume method to discretize the mass- and momentum conservation equations and the generalized minimal residual method in order to solve for the pressure and velocity. The interface between the cement paste and air was tracked by the volume of fluid method [31], which is a free surface tracking algorithm that in an Eulerian frame is considered very accurate [32]. In Figure 4, the model version of the FlowCyl at time zero is illustrated. The inner surface of the FlowCyl was modelled with a wall boundary condition (zero-velocity/no-slip) and the numerically predicted flow resistance ratio was calculated in a similar way as for the experiments, except that the flow rate was determined based on the remaining volume in the simulated domain. A preliminary validation of the CFD model was presented in [13] where it was shown that the simulations predicted the flow 
216 resistance ratio within $10 \%$ accuracy for five different cement pastes, when assuming that the 217 cement pastes could be described by the Bingham material model. In this study, both the 218 Bingham- and H-B material model [33] were used to describe the flow behaviour of all 52 219 cement pastes in order to compare their performance.

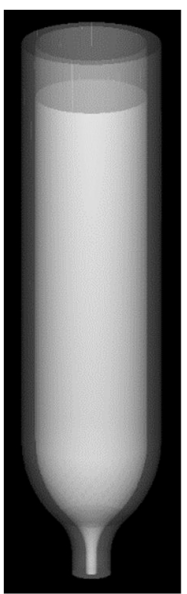

Figure 4: The model version of the FlowCyl at time zero [37].

\section{RESULTS AND DISCUSSION}

226 In Table 2, the rheological parameters for the Bingham- and H-B material model are presented 227 for all 52 cement pastes together with the experimental- and two numerical flow resistance 228 ratios.

229

Tabß30: Experimental and numerical results.

\begin{tabular}{|c|c|c|c|c|c|c|c|c|c|c|c|c|c|c|c|c|c|}
\hline \multirow{2}{*}{$\begin{array}{l}\text { Mix } \\
\text { No. }\end{array}$} & \multicolumn{3}{|c|}{$\begin{array}{c}\text { Flow resistance ratio } \\
\lambda_{Q}\end{array}$} & \multicolumn{2}{|c|}{$\begin{array}{c}\text { Bingham } \\
\text { model } \\
\text { parameters }\end{array}$} & \multicolumn{3}{|c|}{$\begin{array}{c}\text { Herschel- } \\
\text { Bulkley model } \\
\text { parameters }\end{array}$} & \multirow{2}{*}{$\begin{array}{l}\text { Mix } \\
\text { No. }\end{array}$} & \multicolumn{3}{|c|}{$\begin{array}{c}\text { Flow resistance ratio } \\
\lambda_{Q}\end{array}$} & \multicolumn{2}{|c|}{$\begin{array}{c}\text { Bingham } \\
\text { model } \\
\text { parameters }\end{array}$} & \multicolumn{3}{|c|}{$\begin{array}{c}\text { Herschel- } \\
\text { Bulkley model } \\
\text { parameters }\end{array}$} \\
\hline & M & $\begin{array}{l}\text { F-3D } \\
\text { (B) }\end{array}$ & $\begin{array}{l}\text { F-3D } \\
\text { (HB) }\end{array}$ & $\begin{array}{c}\tau_{0} \\
{[\mathrm{~Pa}]}\end{array}$ & $\begin{array}{c}\mu \\
{[\text { Pas }]}\end{array}$ & $\begin{array}{c}\tau_{\mathrm{HB}} \\
{[\mathrm{Pa}]}\end{array}$ & $\begin{array}{c}\mathbf{c} \\
{\left[\operatorname{Pas}^{\mathrm{p}}\right]}\end{array}$ & $\underset{[\mathbf{P a}]}{\mathbf{p}}$ & & M & $\begin{array}{l}\text { F-3D } \\
\text { (B) }\end{array}$ & & $\begin{array}{c}\tau_{0} \\
{[\mathrm{~Pa}]}\end{array}$ & $\underset{[\text { Pas }]}{\mu}$ & $\begin{array}{c}\tau_{\mathrm{HB}} \\
{[\mathrm{Pa}]}\end{array}$ & $\begin{array}{c}\mathbf{c} \\
{\left[\mathbf{P a s}^{\mathrm{p}}\right]}\end{array}$ & $\underset{[\mathbf{P a}]}{\mathbf{p}}$ \\
\hline A-1 & 0.890 & & & 9.36 & & 9.39 & & 1.00 & B-1 & 0.810 & 22 & & 7.11 & & 6.99 & 0.74 & 0.99 \\
\hline A-2 & 0.920 & 891 & 0.906 & 14.27 & 1.26 & 14.40 & 1.12 & 1.01 & B-2 & 0.849 & 0.869 & 0.849 & 8.32 & 0.9 & 8.59 & 0.92 & 1.01 \\
\hline A-3 & 0.960 & 920 & 929 & 23.98 & 1.40 & 20.67 & 2.25 & 0.89 & B-3 & 0.873 & 0.894 & 0.873 & 11.34 & 1.12 & 11.16 & 1.16 & 0.99 \\
\hline A-4 & 0.580 & 0.628 & 0.605 & 2.72 & 0.26 & 2.23 & 0.37 & 0.91 & B-4 & 0.780 & 0.798 & 0.780 & 4.15 & 0.62 & 4.71 & 0.51 & 1.05 \\
\hline A-5 & 0.590 & 0.678 & 0.647 & 5.02 & 0.31 & 3.40 & 0.76 & 0.80 & B-5 & 0.792 & 0.814 & 0.792 & 4.42 & 0.68 & 5.53 & 0.47 & 1.09 \\
\hline A-6 & 0.650 & 0.713 & 0.693 & 4.85 & 0.38 & 3.77 & 0.65 & 0.88 & B-6 & 0.814 & 0.826 & 0.814 & 4.59 & 0.80 & 5.13 & 0.69 & 1.03 \\
\hline A-7 & 0.390 & 0.481 & 0.458 & 1.69 & 0.10 & 0.86 & 0.36 & 0.72 & B-7 & 0.755 & 0.766 & 0.755 & 3.52 & 0.53 & 3.78 & 0.48 & 1.03 \\
\hline A-8 & 0.410 & 0.493 & 0.474 & 1.76 & 0.11 & 1.02 & 0.33 & 0.75 & B-8 & 0.767 & 0.791 & 0.767 & 1.69 & 0.62 & 3.32 & 0.33 & 1.15 \\
\hline A-9 & 0.430 & 0.509 & 0.473 & 1.84 & 0.12 & 1.08 & 0.34 & 0.77 & B-9 & 0.820 & 0.844 & 0.820 & 1.91 & 0.90 & 4.50 & 0.45 & 1.16 \\
\hline A-10 & 0.840 & 0.871 & 0.861 & 11.04 & 0.84 & 9.26 & 1.26 & 0.91 & B-10 & 0.753 & 0.773 & 0.753 & 1.64 & 0.56 & 2.85 & 0.34 & 1.12 \\
\hline
\end{tabular}




\begin{tabular}{|c|c|c|c|c|c|c|c|c|c|c|c|c|c|c|c|c|c|}
\hline A-11 & 0.890 & 0.883 & 0.905 & 16.79 & 1.09 & 14.34 & 1.67 & 0.90 & B-11 & 0.731 & 0.751 & 0.731 & 1.63 & 0.49 & 2.68 & 0.30 & 1.12 \\
\hline A-12 & 0.950 & 0.922 & 0.927 & 25.95 & 1.33 & 19.70 & 3.01 & 0.81 & B-12 & 0.782 & 0.801 & 0.782 & 1.43 & 0.69 & 3.28 & 0.36 & 1.15 \\
\hline A-13 & 0.570 & 0.623 & 0.605 & 2.73 & 0.25 & 2.14 & 0.39 & 0.90 & B-13 & 0.554 & 0.553 & 0.554 & 1.39 & 0.17 & 1.20 & 0.22 & 0.95 \\
\hline A-14 & 0.570 & 0.648 & 0.618 & 3.73 & 0.27 & 2.75 & 0.52 & 0.85 & B-14 & 0.581 & 0.562 & 0.581 & 1.64 & 0.20 & 1.30 & 0.28 & 0.92 \\
\hline A-15 & 0.550 & 0.643 & 0.596 & 4.40 & 0.25 & 3.22 & 0.56 & 0.81 & B-15 & 0.569 & 0.565 & 0.569 & 1.44 & 0.19 & 1.31 & 0.22 & 0.97 \\
\hline A-16 & 0.350 & 0.431 & 0.397 & 1.19 & 0.07 & 0.67 & 0.23 & 0.75 & B-16 & 0.513 & 0.483 & 0.513 & 1.04 & 0.13 & 0.57 & 0.25 & 0.85 \\
\hline A-17 & 0.380 & 0.481 & 0.431 & 1.49 & 0.10 & 0.81 & 0.30 & 0.74 & \begin{tabular}{|l} 
B-17 \\
\end{tabular} & 0.551 & 0.534 & 0.551 & 1.00 & 0.17 & 0.73 & 0.23 & 0.93 \\
\hline A-18 & 0.490 & 0.557 & 0.521 & 1.86 & 0.17 & 1.08 & 0.38 & 0.81 & B-18 & 0.598 & 0.592 & 0.598 & 1.23 & 0.23 & 1.08 & 0.26 & 0.97 \\
\hline A-19 & 0.930 & 0.921 & 0.917 & 16.45 & 1.37 & 13.61 & 2.04 & 0.91 & B-19 & 0.501 & 0.433 & 0.501 & 0.75 & 0.12 & 0.39 & 0.21 & 0.87 \\
\hline A-20 & 0.990 & 0.950 & 0.950 & 32.15 & 1.88 & 21.63 & 4.81 & 0.78 & B-20 & 0.519 & 0.508 & 0.519 & 0.57 & 0.14 & 0.39 & 0.18 & 0.94 \\
\hline A-21 & 1.000 & 1.000 & 0.987 & 75.05 & 3.36 & 33.84 & 17.90 & 0.62 & B-21 & 0.557 & 0.520 & 0.557 & 0.64 & 0.18 & 0.55 & 0.20 & 0.98 \\
\hline A-22 & 0.720 & 0.776 & 0.764 & 6.13 & 0.52 & 4.68 & 0.87 & 0.88 & B-22 & 0.474 & 0.397 & 0.474 & 0.69 & 0.10 & 0.19 & 0.24 & 0.81 \\
\hline $\mathbf{A}-23$ & 0.770 & 0.791 & 0.796 & 8.02 & 0.60 & 6.37 & 1.00 & 0.88 & B-23 & 0.478 & 0.453 & 0.478 & 0.43 & 0.10 & 0.18 & 0.16 & 0.89 \\
\hline A-24 & 0.830 & 0.822 & 0.842 & 9.87 & 0.73 & 9.13 & 0.90 & 0.95 & B-24 & 0.518 & 0.467 & 0.518 & 0.41 & 0.14 & 0.27 & 0.17 & 0.95 \\
\hline A-25 & 0.520 & 0.565 & 0.551 & 2.08 & 0.18 & 1.60 & 0.30 & 0.88 & & & & & & & & & \\
\hline$A-26$ & 0.580 & 0.607 & 0.552 & 2.64 & 0.23 & 2.14 & 0.35 & 0.90 & & & & & & & & & \\
\hline A-27 & 0.600 & 0.650 & 0.627 & 3.54 & 0.28 & 2.73 & 0.48 & 0.87 & & & & & & & & & \\
\hline
\end{tabular}

Abbreviations used in the table:

$\mathbf{M}=$ measured flow resistance ratio $\lambda_{\mathrm{Q}}$.

F-3D (B) = flow resistance ratio obtained with the Flow3D CFD model, using the Bingham material model.

F-3D $(\mathbf{H B})=$ flow resistance ratio obtained with the Flow3D CFD model, using H-B material model.

231

232 4.1. Bingham material model vs. H-B material model

233 The objective of this study is, as mentioned in the introduction, to evaluate whether the flow

234 resistance ratio can be used as a single parameter to describe the flowability of cement paste.

235 However, in order to get to this point, it is necessary to quantify the error that is introduced by

236 going from a three-parameter model (the H-B material model) to a two-parameter model (the

237 Bingham material model). The quantification of this error is carried out by the numerical model.

238 In Figure 5, the difference between the experimental flow resistance ratio and the two numerical

239 predictions are presented. The plot illustrates that for either of the two numerical predictions,

240 the difference does not exceed $30 \%$ in the $\lambda_{\mathrm{Q}}$ range of 0.3 to 1.0 , and the agreement improves

241 when increasing the flow resistance ratio. As reported in [34], a typical range of measurable $\lambda_{\mathrm{Q}}$

242 for cements pastes will vary between $0.30-0.75$, which also corresponds well to the range of

243 values measured for the pastes studied in the paper. The improvement in the observed difference

244 between the measured and predicted values might be a consequence of the no-slip boundary

245 condition and/or the rheological approximation functions favouring a slow flow. Furthermore,

246 Figure 5 demonstrates that generally the best agreement is obtained, when using the H-B

247 material model in the numerical simulations. The average difference in absolute values for the

248 Bingham and H-B material model is 6.5 and $4.6 \%$, respectively, thus illustrating that an

249 additional error of approx. $2 \%$ can be expected when assuming the two-parameter material

250 model instead of the three-parameter material model. This error is specific for the flow 
251 condition in the FlowCyl where the shear rates can vary in the order of $0-2901 / \mathrm{s}$, see Figure

2526 that presents simulation results for mix No. A-6. Note that these shear rates are experienced 253 at a height of $25 \mathrm{~cm}$, which is in the middle of the measuring interval, and that greater shear 254 rates are experienced at the start of the measuring interval $(35 \mathrm{~cm})$, as the hydrostatic head is 255 larger. Within the shear rate interval $0-2901 / \mathrm{s}$, the two material models approximate the 256 measured rheological data as seen in Figure 7 for mix No. A-6. The rheometer experiments are 257 carried out up until a shear rate of $601 / \mathrm{s}$, whereas the shear rates in the FlowCyl are greater, as 258 predicted by the numerical simulations, see Figure 6. This is a source of error that leads to a 259 difference between the experimental and numerical flow resistance ratio. In addition, there 260 could also be a potential error associated with how good the models are able to approximate the 261 actual rheological response of the materials, which was found to be more precise in the case of 262 the H-B model, see Figure 6. Figure 7 shows that at shear rates above $601 / \mathrm{s}$, the material models 263 start to deviate from each other, which is the main reason for the difference in the predicted 264 flow resistance ratios between the two models shown in Figure 5. The shear rate interval 265 experienced by the cement paste during concrete mixing and placement is in the order $0-701 / \mathrm{s}$

266 [35]. This upper shear rate limit is less than the one experienced in the FlowCyl, which indicates 267 that modifying the flowrate in the FlowCyl to lower the shear rate is relevant.

\subsection{Effect of the rheological properties on the measured flow resistance ratio}

271

272 Knowing that the error that is introduced going from the H-B- to the Bingham material model is relatively sparse (see previous section), the rest of the analysis focus on going from a twoparameter (the Bingham material model) to a one-parameter (the flow resistance ratio) flow characterization. In Figure 8 and Figure 9, the experimental flow resistance ratio is plotted as

274 function of the plastic viscosity and yield stress, respectively. In the figures, additional 42 275 results from a previous study [16] are included in order to cover a broader rheological interval. 276 The mixes in [16] were carried out with ten different types of fillers, fi/c ratios by volume 277 ranging from 0.4 to 0.5 , a w/c ratio of 0.5 , and constant SP dosage of $0.50 \%$ per mass cement. 278 Figure 8 shows that all the measurements collapse on the same curve in the flow resistance ratio 279 vs. plastic viscosity plot, whereas Figure 9 shows that the same trend is not the case for the flow 280 resistance ratio vs. yield stress plot. This illustrates that the plastic viscosity dominates the flow 281 resistance ratio, a finding that theoretically was predicted by the numerical model as seen in 282 [13]. This can be illustrated by the following example where the apparent viscosity is calculated 283 for mix No. A-6 at the outlet as well as for two hypothetical cement pastes; one where the yield 
284

stress is increased with $50 \%$ and another where the plastic viscosity is increased with $50 \%$, both as compared to mix No. A-6. The three cement pastes have the following rheological properties: 1) $\tau_{0}=4.85 \mathrm{~Pa}$ and $\mu=0.38 \mathrm{Pas}$; 2) $\tau_{0}=7.28 \mathrm{~Pa}$ and $\mu=0.38 \mathrm{Pas}$; and 3) $\tau_{0}=4.85$ $\mathrm{Pa}$ and $\mu=0.57$ Pas. The apparent viscosity is calculated for the three cement pastes at a representative shear rate of $150 \mathrm{~s}^{-1}$. This value is obtained by considering the shear rates at a height of $25 \mathrm{~cm}$ (i.e. the middle of the measuring interval) and then taking the average shear rate over the cross section in the bottom of the FlowCyl.

$\mu_{\mathrm{app}, 1}=\tau / \dot{\gamma}=\tau_{0} / \dot{\gamma}+\mu=4.85 / 150+0.38=0.412$ Pas;

$\mu_{\mathrm{app}, 2}=\tau / \dot{\gamma}=\tau_{0} / \dot{\gamma}+\mu=7.28 / 150+0.38=0.429$ Pas;

$\mu_{\mathrm{app}, 3}=\tau / \dot{\gamma}=\tau_{0} / \dot{\gamma}+\mu=4.85 / 150+0.57=0.602$ Pas.

The above examples show that a $50 \%$ increase in the yield stress (from $4.85 \mathrm{~Pa}$ to $7.28 \mathrm{~Pa}$ ) only makes the apparent viscosity increase by approx. $4 \%$, whereas a $50 \%$ increase in the plastic viscosity (from 0.38 Pas to 0.57 Pas) makes the apparent viscosity increase by approx. $50 \%$. This example explains why the flow resistance ratio primarily depends on the plastic viscosity of the materials in the FlowCyl. The reason for the dominance is owed to the fact that the cement paste experiences high shear rates at the outlet, see Figure 6, which is a region of the FlowCyl that has a great influence on the flow rate and thereby the flow resistance ratio. These high shear rates lead to apparent viscosities (the viscosity felt by the flowing cement paste) that are dominated by the plastic viscosity in the Bingham material model. As a result, one can state that the flow resistance ratio can be used as a one-parameter characterization of cement paste rheology, as long as the shear rates that the cement paste undergoes in the given application are high. However, this statement only covers a part of the usefulness/limitations of the flow resistance ratio. This is because it is generally accepted that the SP is mainly affecting the yield stress [36], whereas the plastic viscosity is mainly affected by the solid fraction [37]. Therefore, we conducted the "B"-series in this study. Figure 10 shows the plastic viscosity vs. yield stress of the B-series. It illustrates that the SP dosage per cement mass primarily affects the yield stress, as expected, and thereby the slope of the linear relationship between the plastic viscosity and yield stress. Consequently, one single curve cannot represent the flow resistance ratio vs. yield stress measurements, because the flow resistance ratio does not capture the effect of the change in the yield stress. Hence, the SP-dosage per cement mass affects the usefulness of the flow resistance ratio as a one parameter characterization. Further research should 
317 therefore look for ways to make the flow resistance ratio more sensitive to the yield stress, e.g. 318 by lowering the rate of shear in the FlowCyl.

319

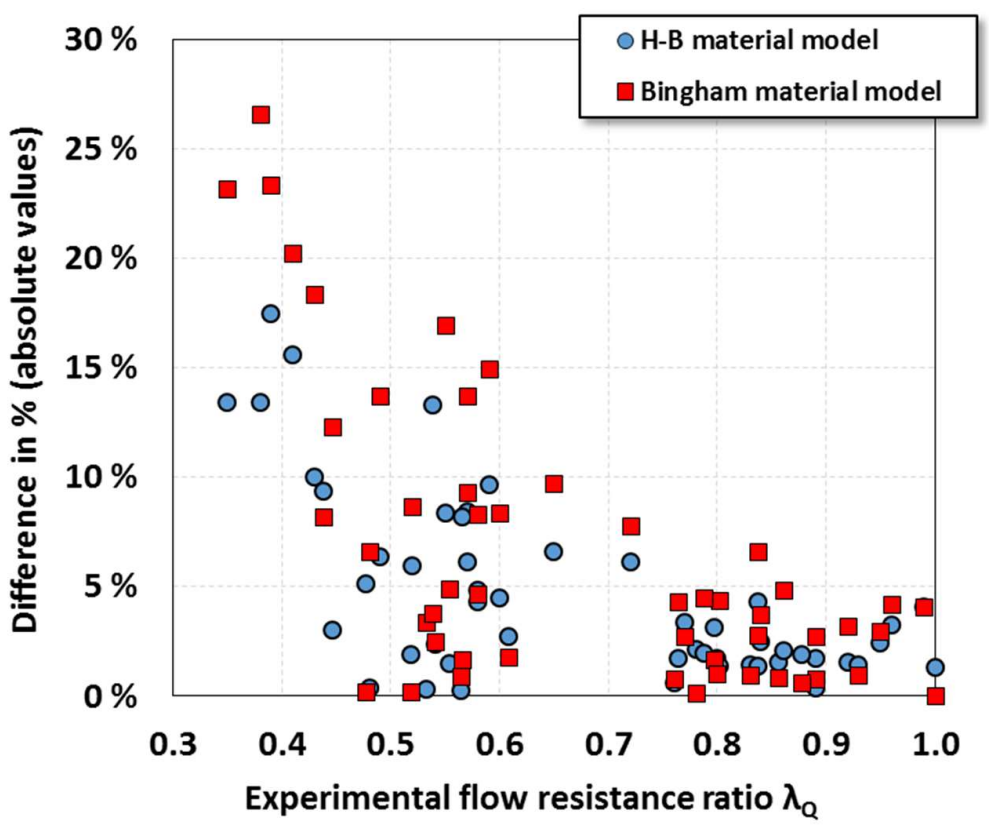

Figure 5: The difference in percentage between the experimental and numerical flow resistance ratio obtained with both the Bingham- and H-B material model. The difference is presented in absolute values. The average difference for the Bingham material model is $6.5 \%$, while it is $4.6 \%$ for the $\mathrm{H}-\mathrm{B}$ material model.

strain rate magnitude
\begin{tabular}{|l|l}
262.518 \\
218.765 \\
175.012 \\
131.259 \\
87.506 \\
43.753 \\
0.000
\end{tabular}

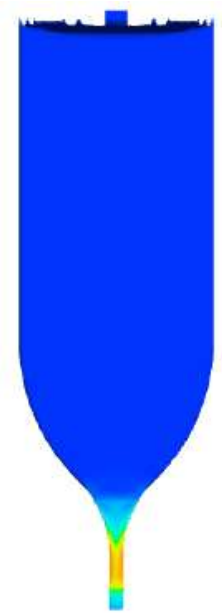

strain rate magnitude
\begin{tabular}{|l|l}
288.924 \\
240.770 \\
192.616 \\
144.462 \\
96.308 \\
48.154 \\
0.000
\end{tabular}

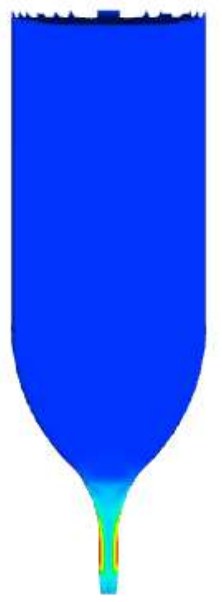

Figure 6: The shear rate magnitude in the cross section of the FlowCyl for mix No. A-6 at a height of $25 \mathrm{~cm}$ : left) Bingham material model right) H-B model. Note that the strain rates are in 1/s. 

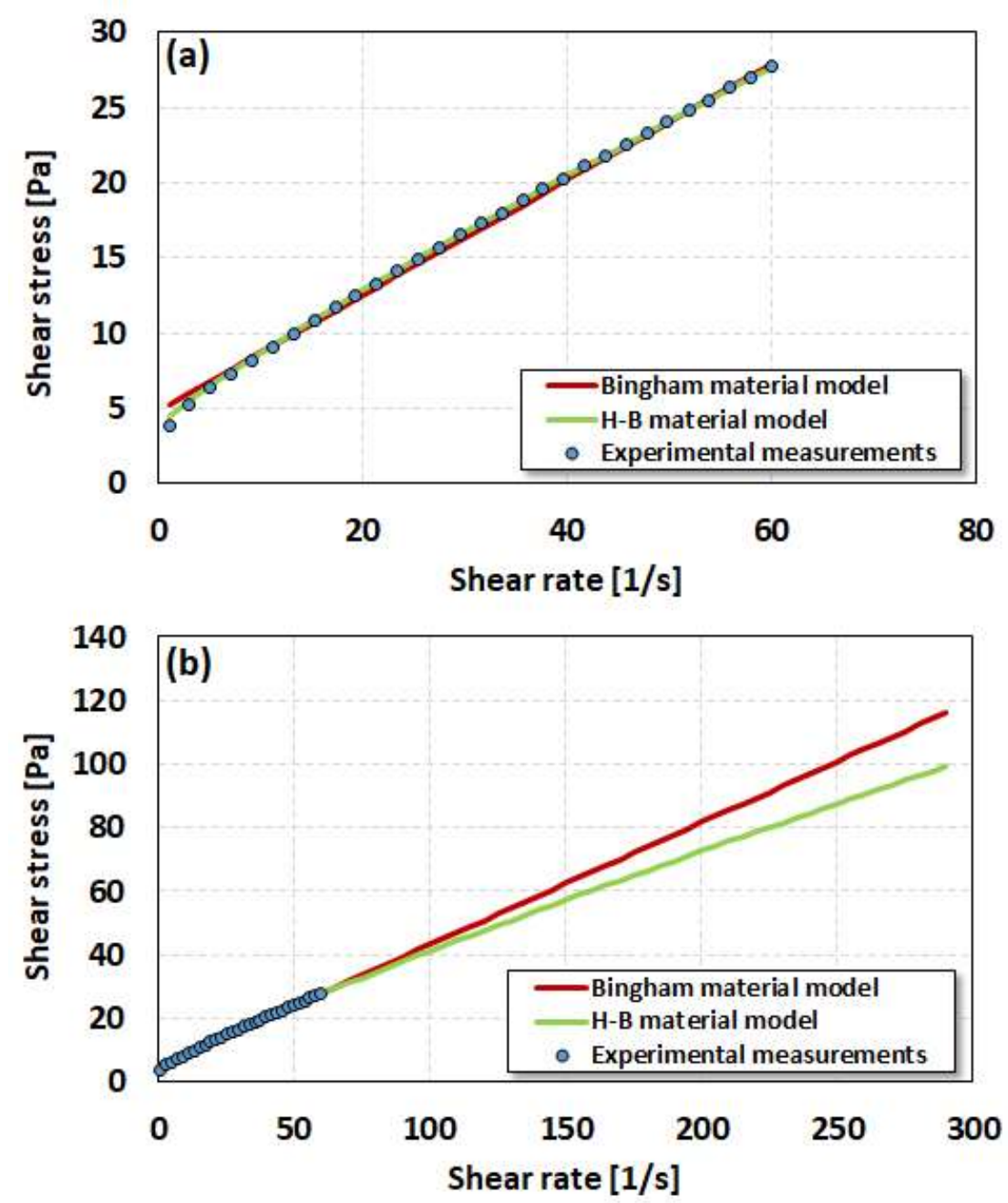

329 Figure 7: The rheological measurements for mix No. A-6 together with the fits based on the Bingham and H-B 


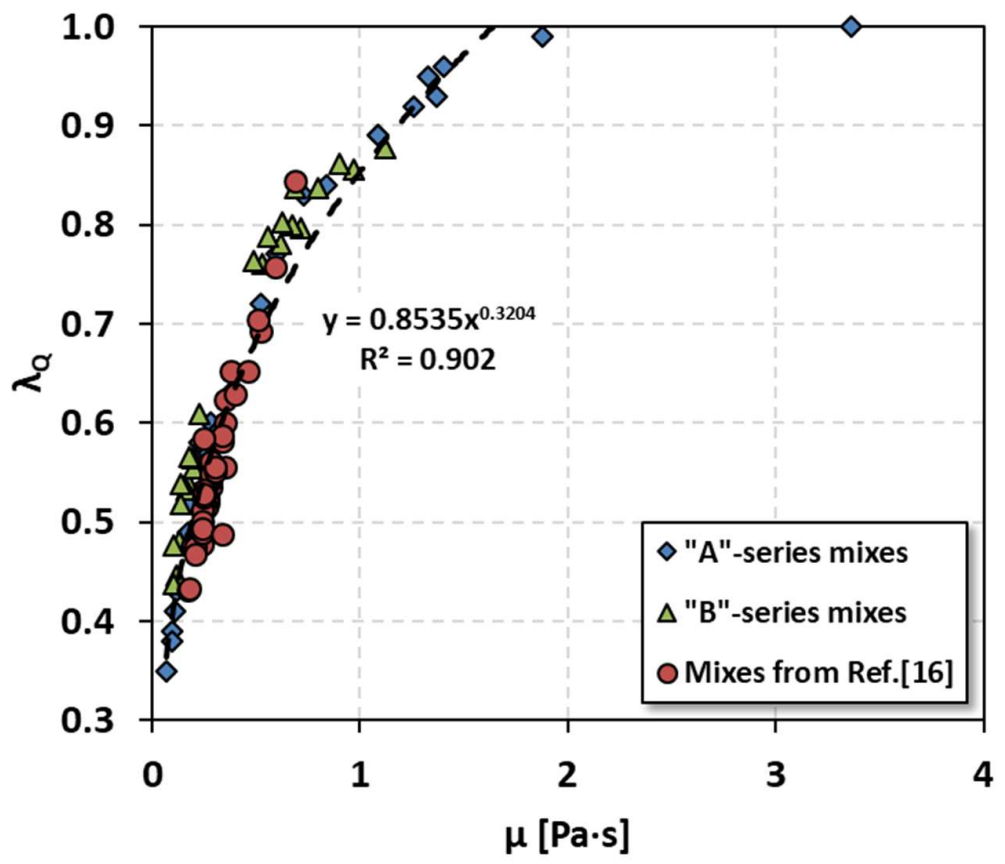

Figure 8: Flow resistance ratio vs. plastic viscosity for all the experiments and mixes from Ref. [16]. Note that the experimental point corresponding to $\lambda_{\mathrm{Q}}=1$ represents a cement paste matrix that was not flowing in the FlowCyl equipment, and this it is in fact its rheological parameters are outside the measurement range of the

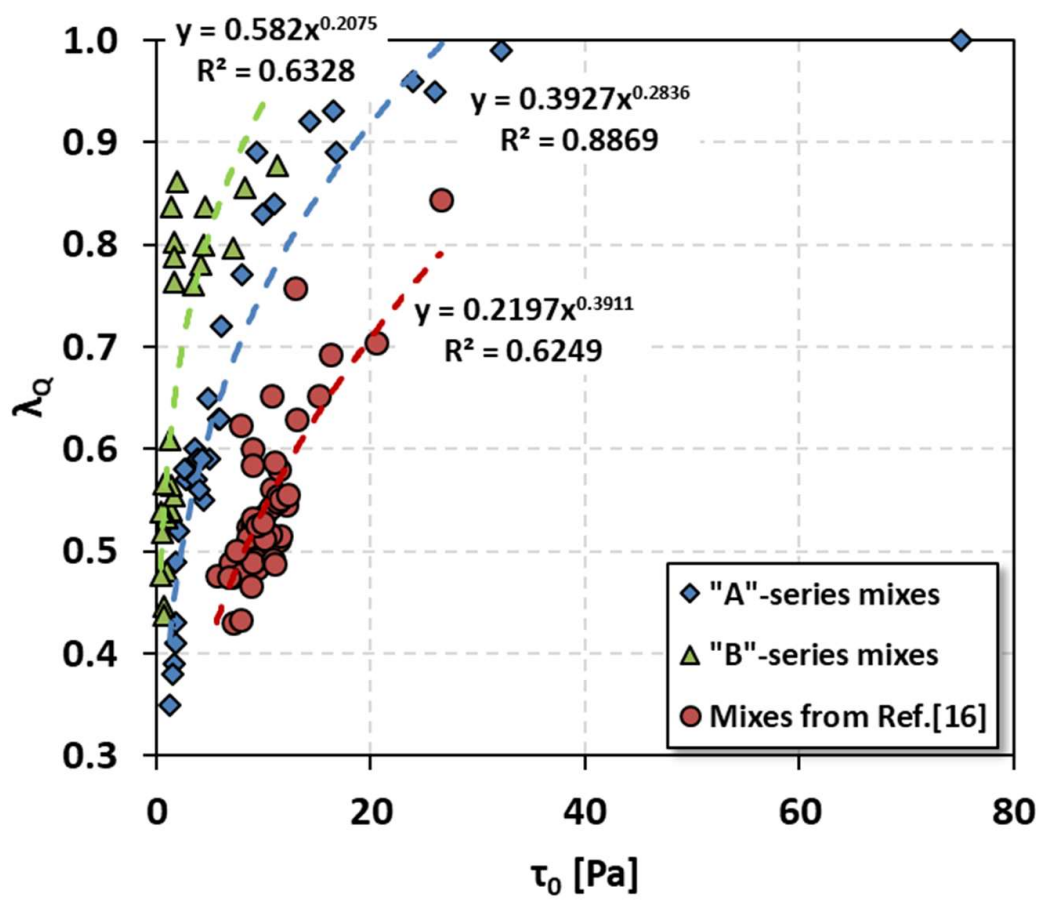

Figure 9: Flow resistance ratio vs. Bingham's yield stress for all the experiments and mixes from Ref. [16]. Note 
FlowCyl equipment, and this it is in fact its rheological parameters are outside the measurement range of the

342 equipment.

343

344

345

346

347

348

349

350

351

352

353

354

355

356

357

358

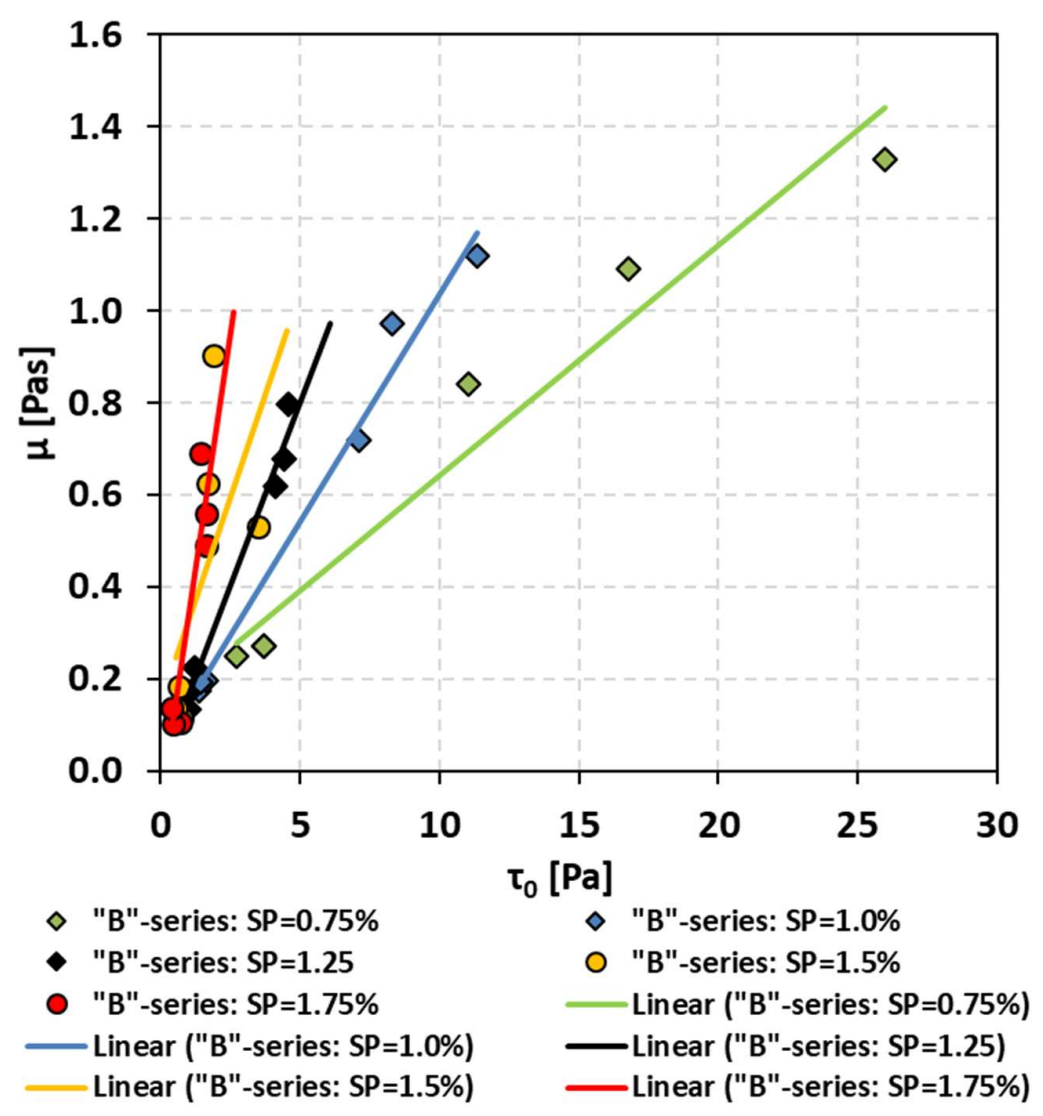

Figure 10: Plastic viscosity vs. yield stress for "B"-series mixes where the SP dosage per cement mass was varied.

\section{CONCLUSIONS}

For the cement pastes investigated experimentally and numerically in this study, the following main conclusions can be drawn with respect to the limitations of the FlowCyl and appertaining flow resistance ratio:

- The average difference between the experimental and numerical flow resistance ratio is $6.5 \%$ and $4.6 \%$ with the Bingham and H-B material model, respectively. Thus, indicating that an additional error of approx. $2 \%$ can be expected when assuming that the cement paste can be described with the two-parameter material model (Bingham material model) instead of the three-parameter material model (H-B material model); 
- All the measurements collapse on the same curve in the flow resistance ratio vs. plastic viscosity plot, which is not the case for the flow resistance ratio vs. yield stress plot. This illustrates that the flow resistance ratio is dominated by the plastic viscosity. This finding is supported by the numerical model that predicts very high shear rates at the outlet. As a consequence, it is argued that the flow resistance ratio can be used as a oneparameter characterization of cement paste rheology, when the shear rates that the cement paste undergoes in a given application are high;

- The SP dosage per mass cement changes the slope of the apparent linear relationship between the yield stress and plastic viscosity. For that reason, it is also argued that the flow resistance ratio can distinguish between the flowability of cement pastes if the SP dosage per mass cement is kept constant;

- Further work will be targeted at changing the FlowCyl design to decrease the shear rate at the outlet and thereby enable the one-parameter flow resistance ratio to become sensitive to variations in the yield stress.

[1] C. Ferraris, K. Obla and R. Hill, "The influence of mineral admixtures on the rheology of cement paste and concrete," Cement and Concrete Research, vol. 31, no. 2, pp. 245-255, 2001.

[2] E. Mørtsell, "Modelling the effect of concrete part materials on concrete consistency. PhD, " Norwegian University of Science and Technology (In Norwegian), 1996.

[3] S. Smeplass, "BE96-3942/R12 Applicability of the particle-matrix model to LWAC," EuroLightCon, Brussels, 2000. 
[4] J. Wallevik, "Rheological properties of cement paste: Thixotropic behaviour and structural breakdown," Cement and Concrete Research, vol. 39, pp. 14-29, 2009.

[5] T. Mezger, The Rheology Handbook: For users of rotational and oscillatory rheometers, Hannover: Vincentz Network, 2006.

[6] R. Shaughnessy and P. Clark, "The rheological behaviour of fresh," Cement and Concrete Research, vol. 18, pp. 327-341, 1988.

[7] D. Feys, R. Cepuritis, S. Jacobsen, K. Lesage, E. Secrieru and A. Yahia, "Measuring rheological properties of cement pastes: most common techniques, procedures and challenges," RILEM Technical Letters, vol. 2, pp. 129-135, 2017.

[8] N. Roussel, C. Stefani and R. Leroy, "From mini-cone test to Abrams cone test: measurement of cement-based materials yield stress using slump tests," Cement and Concrete Research, vol. 35, pp. 817-822, 2005.

[9] N. Roussel and R. Le Roy, “The Marsh cone: a test or a rheological appartus?," Cement and Concrete Research, vol. 35, pp. 823-830, 2005.

[10] R. Le Roy and N. Roussel, "The Marsh Cone as a viscometer: theoretical analysis and practical limits," Materials and Structures, vol. 38, no. January-February, pp. 25-30, 2005.

[11] S. Smeplass and E. Mørtsell, "The applicability of the particle matrix model to self compacting concrete," Nordic Concrete Research, vol. 26, 2001.

[12] T. Hammer and J. Wallevik, "On the correlation between rheology of paste, mortar and concrete," in Proceedings of the Second North American Conference on the Design and Use of Self-Consolidating Concrete (SCC) and the Fourth International RILEM Symposium on Self-Compacting Concrete, Chicago, 2005.

[13] R. Cepuritis, E. Ramenskiy, E. Mørtsell, S. Smeplass, H. Kjos-Hanssen, S. Li, S. Jacobsen and J. Spangenberg, "FlowCyl: one-parameter characterisation of matrix rheology," in Proceedings of the Second Concrete Innovation Conference (2nd CIC), 6-8 March, Tromsø, Norway, 2017.

[14] H. Merkus, Particle Size Measurements. Fundamentals, Practice, Quality, Dordrecht: Springer Science+Business Media B.V., 2009.

[15] S. Ng., H. Mujica and S. Smeplass, "Design of a simple and cost-efficient mixer for matrix rheology testing," Nordic Concrete Research, vol. 51, no. 3, pp. 15-28, 2014. 
[16] R. Cepuritis, "Development of Crushed Sand for Concrete Production with Microproportioning. PhD," Norwegian University of Science and Technology, Trondheim, 2016.

[17] R. Cepuritis, S. Jacobsen, S. Smeplass, E. Mørtsell, B. Wigum and S. Ng, "Influence of crushed aggregate fines with micro-proportioned particle size distributions on rheology of cement paste," Cement and Concrete Composites, vol. 80, pp. 64-79, 2017.

[18] K. Vasilic, W. Schmidt, H. Kühne, F. Haamkens, V. Mechtcherine and N. Roussel, "Flow of fresh concrete through reinforced elements: Experimental validation of the porous analogy numerical method," Cement and Concrete Research, vol. 88, pp. 1-6, 2016.

[19] K. Vasilic, B. Meng, H. Kühne and N. Roussel, "Flow of fresh concrete through steel bars: A porous medium analogy," Cement and Concrete Research, vol. 41, pp. 496-503, 2011.

[20] S. Jacobsen, R. Cepuritis, Y. Peng, M. Geiker and J. Spangenberg, "Visualizing and simulating flow conditions in concrete form filling using pigments," Construction and Building Materials, vol. 49, pp. 328-342, 2013.

[21] L. Shen, L. Struble and D. Lange, "Modelling dynamic segregation of self-consolidation concrete,” ACI Mater. J., pp. 375-380, 2009.

[22] J. Spangenberg, N. Roussel, J. Hattel, H. Stang, J. Skocek and M. Geiker, "Flow induced particle migration in fresh concrete: Theoretical frame, numerical simulations and experimental results on model fluids," Cement and Concrete Research, pp. 633-641, 2012.

[23] J. Spangenberg, N. Roussel, J. Hattel, E. Sarmiento, G. Zirgulis and M. Geiker, "Patterns of gravity induced aggregate migration during casting of fluid concretes," Cement and Concrete Research, pp. 1571-1578, 2012.

[24] J. Wallevik, W. Mansour and O. Wallevik, "OpenFOAM casting solver with segregation. International RILEM conference on materials, systems and Structures in Civil Engineering, Conference segment on Fresh Concrete," in Published by RILEM Publications S.A.R.L. ISBN: 978-2-35158-184-1, 22-24 August, Technical University of Denmark, Lyngby, Denmark, 2016.

[25] O. Svec, G. Zirgulis, J. Bolander and H. Stang, "Influence of formwork surface on the orientation of steel fibres within self-compacting concrete and on the mechanical 
properties of cast structural elements," Cement \& Concrete Composites, vol. 50, pp. 60$72,2014$.

[26] L. Martinie, J.-F. Lataste and N. Roussel, "Fiber orientation during casting of UHPFRC: electrical resistivity measurements, image analysis and numerical simulations," Materials and Structures, vol. 48, pp. 947 - 957, 2015.

[27] H. Le, E. Kadri, S. Aggoun, J. Vierendeels, P. Troch and G. De Schutter, "Effect of lubrication layer on velocity profile of concrete in a pumping pipe," Mater. Struct., vol. 48, pp. 3991-4003, 2008.

[28] J. Wallevik, "Minimizing end-effects in the coaxial cylinders viscometer: Viscoplastic flow inside the ConTec BML Viscometer 3," J. Non-Newtonian Fluid Mech., pp. 116$123,2008$.

[29] A. Gram, J. Silfwerbrand and B. Lagerblad, "Obtaining rheological parameters from flow test - Analytical, computational and lab test approach," Cement and Concrete Research, vol. 63, pp. 29-34, 2014.

[30] N. Roussel, A. Gram, M. Cremonesi, L. K. K. Ferrara, V. Mechtcherine, S. Shyshko, J. Skocek, J. Spangenberg, O. Svec, L. Thrane and K. Vasilic, "Numerical simulations of concrete flow: A benchmark comparision," Cement and Concrete Research, vol. 79, pp. 265-271, 2016.

[31] C. Hirt and B. Nichols, "Volume of fluid (VOF) method for the dynamics of free boundaries," J. Comput. Phys., pp. 201-225, 1981.

[32] R. Comminal, J. Spangenberg and J. Hattel, "Cellwise conservative unsplit advection for the volume of fluid method," J. Comput. Phys., pp. 582-608, 2015.

[33] E. Mitsoulis, "Flows of viscoplastic materials: models and computations," Rheol. Rev., pp. 135-178, 2007.

[34] S. Smeplass and R. Cepuritis, "Chapter 4 - Fresh concrete - proportioning," in TKT 4215 Concrete Technology 1, course compendium, Trondheim, Norwegian University of Science and Technology, 2016, pp. 4.1-4.41.

[35] R. Helmuth, L. Hills, D. Whitting and S. Bhattacharja, "Abnormal Concrete Performance in the Presence of Admixtures. PCA R\&D Serial No. 2006," Portland Cement Association, Skokie, 2006. 
[36] O. Wallevik and J. Wallevik, "Rheology as a tool in concrete science: The use of rheographs and workability boxes," Cement and Concrete Research, vol. 41, no. 12, pp. 1279-1288, 2011.

[37] H. Barnes, J. Hutton and K. Walters, Introduction to Rheology, Amsterdam: Elsevier Science Publishers B.V., 1993.

384 